\title{
Stress Concentrations in Bolt-thread Roots
}

\author{
Frozen-stress three-dimensional stress-analysis techniques \\ were used in first phase of this investigation; the results \\ of these tests were augmented later by fatigue tests \\ and by metallographic inspection of cracked bolts
}

\author{
by James $D$. Chalupnik
}

\begin{abstract}
The apparent geometric origin of fatigue fractures in oversize shank holts is considered in this report. Bolt-nut interaction between the bolt and both a standard nut and a special nut are investigated. The "frozen stress" method of three-dimensional stress analysis was used to determine the magnitudes and locations of points of stress concentration in plastic models of both the oversize shank bolt and a standard bolt in combinations with standard and special nuts.

The results indicate that, for installations in which the special nut is used, bolt geometry may be the controlling factor in determining the fatigue life of the bolt nut combination, because the stress-concentration factors due to the nut loading are of the same order of magnit ude as thestress-concentration factors due solely to bolt geometry. On the other hand, for installations in which standard nuts are used, the nut-induced stress-concentration factor's are much larger than those due to bolt geometry; so. bolt geometry will have less effect on the fatigue performance of the combination. If the nut is threaded onto the bolt so far that the first loaded thread of the nut is in the thread-rurout area of the bolt, fatigue performance of the installation will be greatly reduced due to the combination of stress-concentration factors from thread loading and section change and, again, bolt geometry may be a prominent causative factor.
\end{abstract}

\section{Introduction}

Fatigute fractures were observed in the threadrunout area of several of a certain-size high-strength bolt. Allhough the bolts were presumed to be loaded essentially in shear. the fracture had the appearance of a low-cycle. high-load tensile fracture. The similarity of fractures indicates a geometric origin of the fatigue cracks which led to ultimate loss of the bolts. The bolts were tis oversize shank (") shank diameter) titanium-alloy 11 aluminum-8 vanadium-5 irom bolts rated at 200ksi minimum ultimate tensile strength based on the pitch diameter. Nuts used on all of the fractured bolts had a special throid design called the "EquaStress" thread by the minufacturer Elastic Stop

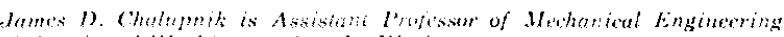

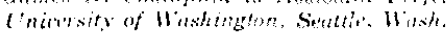

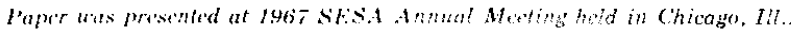

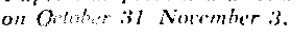

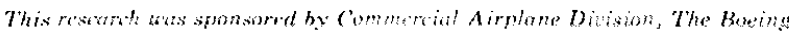
Compony. Rinlon, Wish.
}

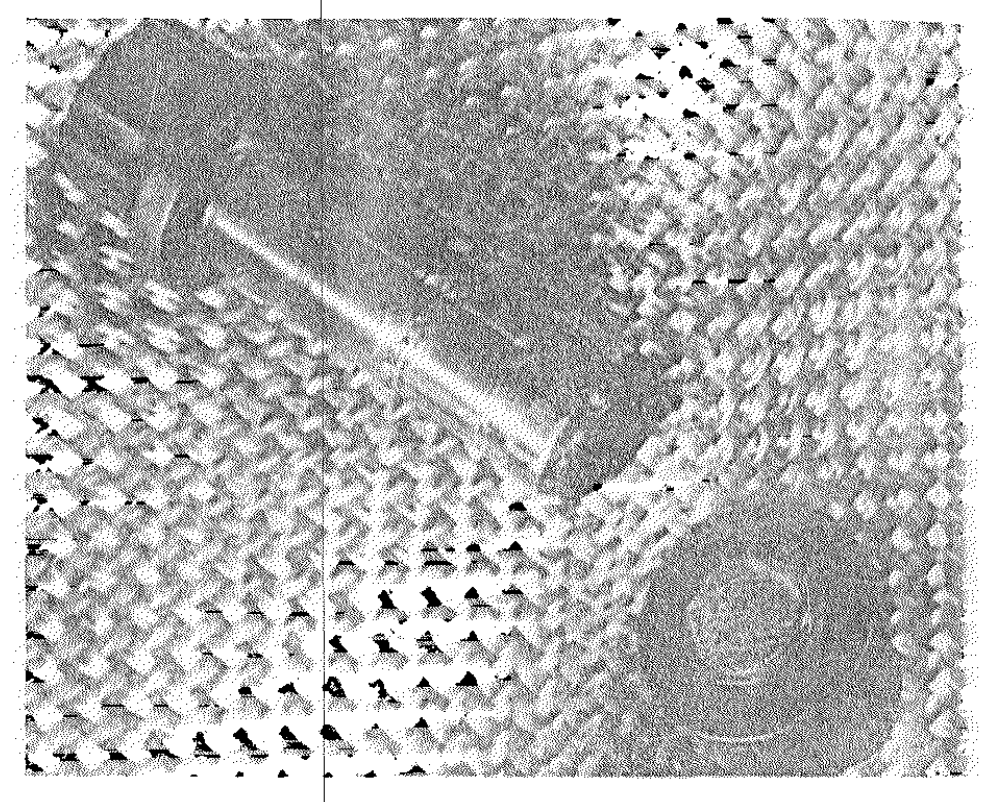

Fig. 1-Fracture of an oversize boit in thread. $\mathrm{w}=\mathrm{ex}$

Nut Company. A typical fracture is ine of the subject bolts is shown in Fig. 1 .

Fractures were nomally observert in : $e^{\circ}$ bolt; buwever. it is a well known fact that atisie performance of a bolt is largely dependeni on the mat-

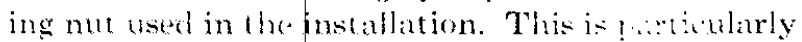
important in this instance. where the nas is specif-

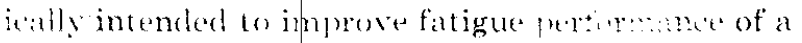
holt.

A number of questions were raised in ... result of these fractures. In order to obtail: answers to as many of the cuestingns as possible, a stres-inalysis program of the hole design was iniliated Frozenstress thee-dimensional stress-amalysis cedmigues were lised in the first phase of the invesigntion, and the results of these tests were augme mied hy tiague lests and by metallographic inspedang ot the cracked bolts in a bater phase.

Results of the threedimensionat aredastic stress analysis of the orersize shank he: with both standard and siredigl nuts are comparen an results 
for a standard bolt under the same conditions in this report.

\section{Previous Work}

Much has been written about screw fasteners and their applications but, even so, the volume of these reports is small when one considers the massive use of these devices in industry. Published reports of actual stress analysis of screw fasteners are few, no doubt due to the complicated geometry of the screw fastener. Because of the geometrical difficulties. many of the significant analyses of stresses in screw fasteners have been experimental in nature and. generally, they utilize photoelastic techniques.

An early attempt at a purely analytical solution of stress distributions in bolts and nuts was given by Stromeyer: and another was undertaken by Den Hartog.: These analyses are interesting and provide an insight into the loading of threaded parts in that they account in a qualitative way for the increase in thread loading from the top to the bottom of the nut. Both papers lack something in completeness. because the calculations are based on a thread elasticity which is calculated for a two'imensional thread. and must necessarily be in error. It is truc. however, that since the problem is one in elasticity. the shape of the load-distribution curve should he the same, and only the scale of magnitude would he changed by considering the morecorret three-dimensional thread.

Typical early experimental investigations used two-dimensional photoelastic models; descriptions of these experimental investigations are given in the papers of Solakian, ${ }^{3}$ Hall, ${ }^{+}$and Heywood." Goodier analyzed thread loads using the unique experimental technique of measuring the external displacenents of a cylindrical nut and relating these displacements to the thread loads and stresses.

The results of all these investigations show essentially the same thing, that, in standard nuts, the first threads carry the largest portion of the load and thereby impose large stress concentrations in the bolt in this region. The two-dimensional photoelastic studies indicated that the area of highest stress concentration was located in the root area of the bolt threads, but there was disagreement as to the magnitude and even some uncertainty as to exactly which bolt thread carries the lieaviest load.

Failure of two-dimensiomal photoelastic methods to vield useful data can be attributed to two causes:

1 : the difficulty involved in accurately machining the two-dimensional screw threads, and (2) the basic inability of the two-dimensional model to duplicate the three-dimensional stress distribution existing in screw fasteners.

One of the first reports of three-dimensional stress analysis of threaded fasteners in given by Horger and Buckwalter in a paper which also gives results of fatigue tests on several bolt-nut combina- tions. Not long thereafter, Hetényi published a paper which contains in this author's opinion the most information available in one source about stress concentrations in nuts and bolts. Hetényi investigated the effect of six different nut designs on the stress distribution in bolts. This paper points out the importance of investigating the interaction of the nut and bolt in threaded fasteners and has particular significance in the investigation outlined in this report.

The work of Hetényi, and Horger and Buckwalter serves to demonstrate the usefulness of three-dimensional frozen-stress techniques in the investigation of stress distributions and stress concentrations in nut-bolt combinations.

\section{Frozen Stress}

A brief description of the frozen-stress method may be useful at this point. It is assumed that the reacler is accuainted with the photoelastic phenomenon.

In frozen-stress investigation, advantage is taken of the two-phase nature of many birefringent materials. It is convenient to think of the material as being composed of a coarse lattice. the interspaces of which are filled with a riscous second phase. At room temperature, the viscous phase is essemtially chastic; however, at elevated temperattures, its viscosity is greatly reduced and it flows freely. under externally applied loads. The first or lattice phase remains elastic to much higher temperatures and, consequently. carries all the load at higher temperatures.

When a model made of a material displaying this two-phase behavior is loaded and placed in an oven in which the temperature is raised sufficiently to permit the viscous phase to flow. the lattice phase assumes the total load-carrying role. If the temperature is then lowered while the load is still applied, the viscous phase will stiffen and "lock" or "freeze" the stresses in the lattice phase of the plastic. Plane sections removed from the model can be analyzed by conventional two-dimensional photoelastic stress-analysis techniques. Due to the approximate axial symmetry of nuts and bolts, diametral sections are well suited to photoelastic stress analysis and contain the important information pertaining to the stresses in the screw threads.

\section{Scope of Investigation}

It was desired to compare the oversize-shank bolt configuration with standard bolt configuration in applications with both the standard and the special nuts. Four combinations were required. Two stud bolts were manufactured, one with a standard and one with an oversize shank, and two standard and two special nuts were manufactured, one each for each bolt. All parts were machined from precast $\mathrm{Hys}$ ol birefringent plastic.

The Hysol nuts and bolts were four times scale 


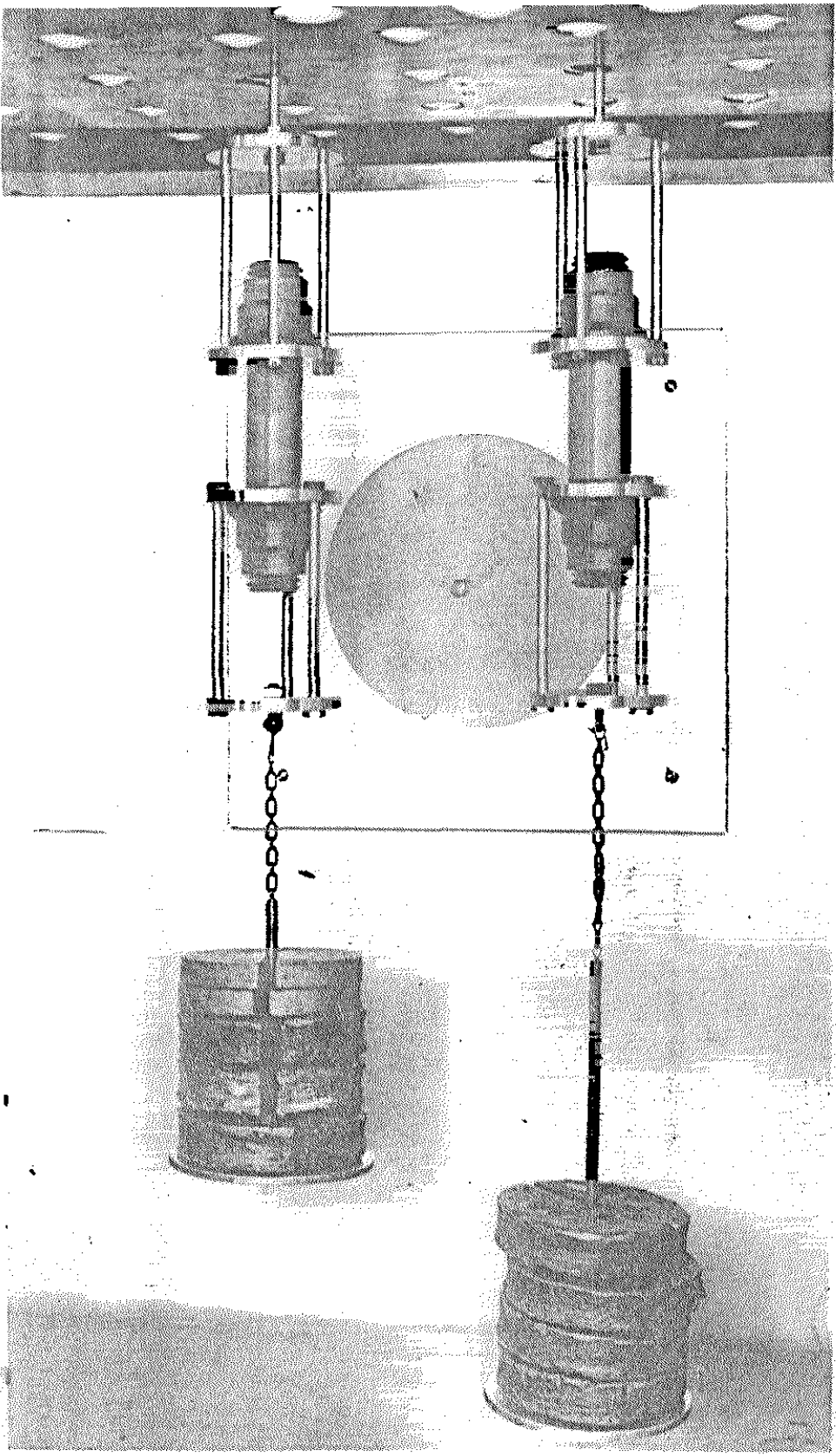

Fig. 2-Loaded models in oven

model of their 0.3125 -in. -24 UNJF counterparts and had $1^{1}$ :-in. -6 threads scaled up from MIL-S-8879 specifications. This specification provides for a liberal root ridlus on bolt threads and a truncated nut thread. MIL-S-8879 is the controlling document for the threads on the fastener under investigation.

Nut and bolt assemblies, threaded to simulate engagement encountered in typical installations, were placed in a controlled oven, loaded and annealed. The loid on the specimens represented a preload on the bolts corresponding to roughly 140,000 psi bised on the pitch diameter. Figure 2 shows the models loaded in the oven preparatory to the amnealing operation.

When the ammealing operation was completed, the models were removed from the fixtures, im- mersed in a small mineral-oil-filled tank, and riewed in the polariscope to get a quick check on the extent of the frozen stresses locked in the models and to check for evidence of excessive bending stresses. The models were then sectioned and again viewed in the polariscope. The sections were photographed and inspected optically to determine the magnitudes and locations of points of stress concentration. The results of these observations are presented in a subsequent section of this report.

\section{Experimental Program}

\section{Preparation of Specimens}

Model nuts and bolts were prepared from precast Hysol CP5-4290 birefringent plastic. Care was exercised in machining the models from the plastic stock to insure conformance with threadprofile specifications and surface finish, and to insure that the models were free of locked-in stresses sometimes caused by heat generated during the machining operations. The machinist who performed the machining operations on the models is experienced in machining Hysol plastic and is aware of the special precautions which must be taken in machining it. The quality of his work on the nut and bolt models was generally high, as can be seen in the photographs in this report.

\section{Loading and Annealing}

The models were assembled with one standard and one special nut on each bolt, suspended inside the annealing oven, and loaded with a dead weight of $20 \mathrm{lb}$. Self-aligning harnesses were used for hanging the models and for applying the load to the models. Washers made of blotting paper were used between the harnesses and the nuts to provide for more uniform load transfer to the nut models. The loaded models are shown in the annealing oven in Fig. 2.

The room-temperature modulus of elasticity for the Hysol is 480,000 psi but, at $270^{\circ} \mathrm{F}$, the modulus is only 2,190 psi. Tensile strength at $270^{\circ} \mathrm{F}$ is 210 psi and Poisson's ratio is $\mathbf{0 . 5}$. The fringe value, which is a measure of the photoelastic sensitivity of the material, is $1: 35 \mathrm{psi}$ fr/in. Fringe orders for ${ }^{1}{ }^{-i n}$.in sections of the shank portion of the model bolts were calculated to be 1.25 fringe for the oversize and 1.51 fringe for the standard-shank bolt for the 20-lb load. This loading is equivalent to a tensile stress in the prototype bolt of about 140,000 psi based on the pitch diameter of the threads or 115,000 psi in the standard shank and 95.000 psi in the oversize shank.

\section{Polarisope}

All fringe photographs and all fringe-order counts were taken on a diffused-light polariscope. Light source is a bank of 17 15-w fluorescent tubes behind a frosted Plexiglas diffuser. The polarizer, analyzer and the two quarter-waves plates are 10 
in. in diameter and are independently rotatable.

Green fluorescent tubes were used for illumination for the black-and-white photographs. The green tubes do not provide monochromatic light, hut their output covers a relatively narrow spectral band and they are a satisfactory light source, provided the proper film is used. Kodax Commercial Process Ortho film was used for the black-andwhite photographs and the film was developed and printed for contrast. Commercial Process Ortho film is highly sensitive to green light; so, the combination provided good fringe photographs. Coolwhite fluorescent tubes were used for making the color photographs and for illuminating the models for the telescope examination. Kodak Ektacolor Professional Type " $\mathrm{S}$ " film was used for the color photographs.

\section{Preliminary Inspection of Fringes}

Immediately following the annealing process, the models were removed from the oven and placed in a small, square Plexiglas tank filled with mineral oil and inspected optically and photographed in the polariscope. Mineral oil has essentially the same refractive index as Hysol and, consequently, permits the observation of fringes in the eylindrically shaped bolt shank without distortion. In this case, the fringes could be observed to within ${ }^{1}{ }_{32}$ in. or less from the edge of the bolt.

These initial observations were matle to determine the fringe order of the stress pattern frozen in the models and to determine the amount of bending introduced by the loading process prior to sectioning the models. Had an undesirable loading condition been noted, the model could have been reloaded and annealed (several times if necessary) until the desired loading conditions were obtained before the expensive models were destroyed by sec-
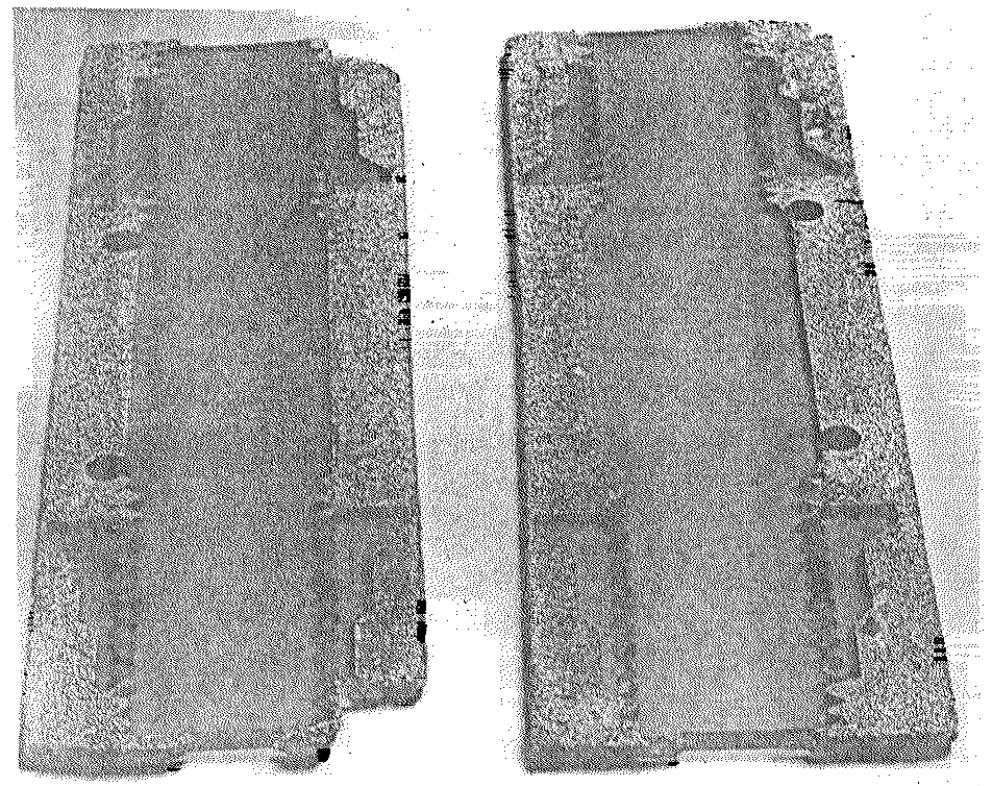

Fig. 3-Sectioned models tioning. The method of determining fringe order in the unsectioned bolt is described below.

Stress distribution in a cross section of the shank portion of a bolt is essentially uniform; consequently, by plotting the fringes in the photographs of the unsectioned shank on a cross-section view of the bolt, it was possible by interpolation to determine the fringe order in a slice cut from this portion of the bolt. Calculations indicated that the fringe level in the shank of the oversize bolt would be about 1.1 fringe and that in the standard bolt shank would be about 1.4 fringe for an ${ }^{1}$ 's-in.-thick section. Largest bending moment was found in the oversize bolt; however, the maximum bending stress was less than 5 percent of the tensile stress. This was considered to be satisfactory; so, the specimens were prepared for sectioning.

\section{Sectioning of the Models}

It is considered desirable to section the bolt and nuts as a unit, but it was not considered wise to use normal shop methods for holding the models during the sectioning operations, because of the probability of locking in undesirable stress patterns. A highly satisfactory solution to this problem was found, however. Small wooden boxes were fahricated into which the bolt assemblies were placed, coffin fashion. The space around the bolt and nuts was then filled with a rigid, epoxy foam that was foamed in place. The foam set up and bonded to the test pieces in a matter of minutes and the wooden boxes provided solid material for clamping in shop machines. Both slices of the photoelastic plastic bolts in their epoxy foam jackets are shown in Fig. 3.

The slices were rough cut with a band saw. then the faces were machined smooth, flat and parallel with a fly cutter in a milling machine. The thickness was held to $0.125=0.001 \mathrm{in}$. over the section; so, no corrections for thickness variations were required.

A dull band-saw blade was used accidentally on one of the roughing cuts, and as a result, a number of bolt threads were chipped on the oversize bolt section. The damage was more esthetic than functional, since the pertinent data sought in this investigation was contained essentially in the root section of the bolt threads, and this part of the model was not damaged.

\section{Detailed Inspection of Fringes}

The photoelastic pictures of the sectioned nut and bolt combinations are shown in Fig. 4. Areas of stress concentration in the bolts are readily identified as the roots of the threads. In these areas, the tensile bending stresses due to the beam-ty pe loading of the bolt threads combine with the stresses due to the tensile load on the bolt at a point where the latter stresses are concentrated due to the notch effect of the thread.

The fringes in the photographs can be counted 


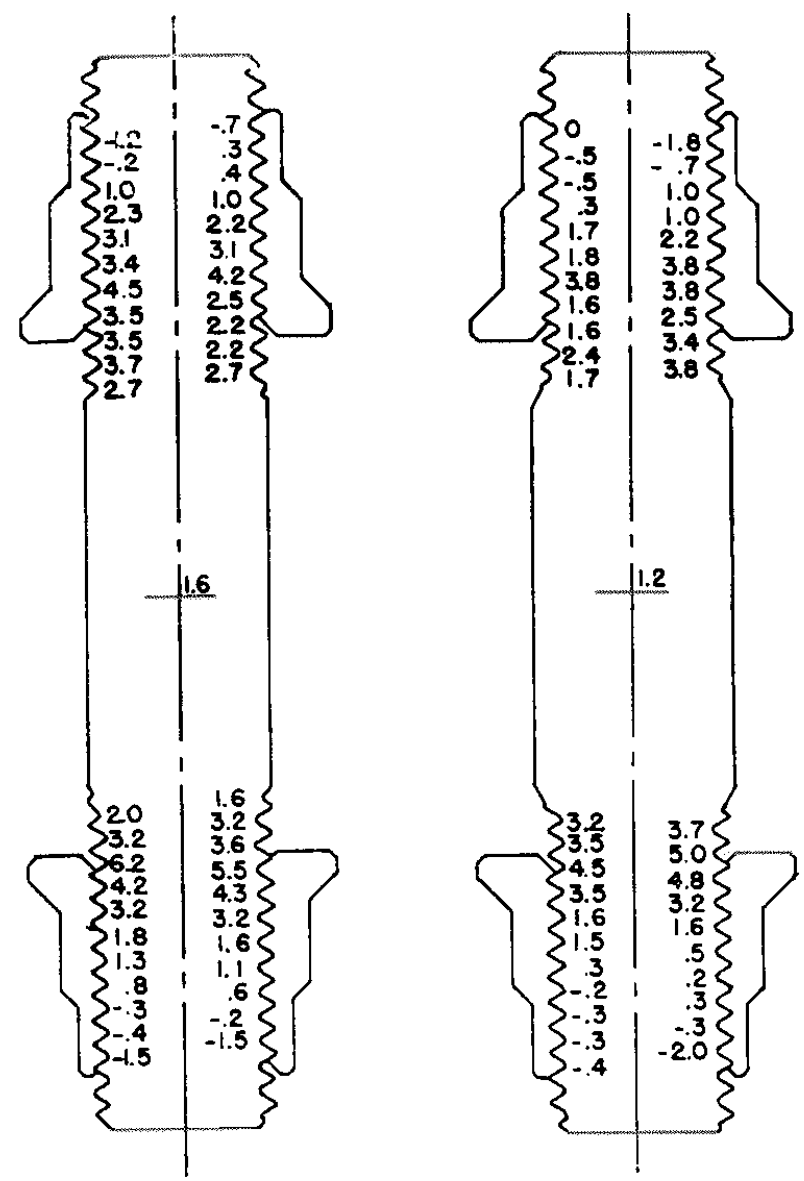

Fig. 5-Fringe-order maxima for standard and oversize bolts. (Standard nuts are at bottom)

Fortunately, this is a point of uniaxial stress and stress is proportional to fringe order here also.

\section{Test Results}

Maximum fringe orders obtained from the telescopic investigation are shown in Fig. 5 . In each case, the maxima were found in the threadroot area. Results from Fig. 5 are shown graphically in Fig. 6 for the section of the bolt that mates with the nut. Results from both standard and oversize bolts are plotted on the same graph. It will be noted that the results lie very close to each wher and the curves are drawn in to "guide the eye through the points." It can be seen immediately that the special nut offers a reduction in maximum stress compared to the standard nut. The recluction amounts to approximately onethird of the maxinum stress encountered with the standard nut. This is accomplished by providing relief in the root of the nut thread which imparts a certain amount of flexibility to the nut thread and permits some of the upper threads to share the load-carrying function.

It would be wrong, on the basis of these results, to say that the special thread permits more threads to carry the load, since it will be noted that the first two "engirged" threads in the bolt ends
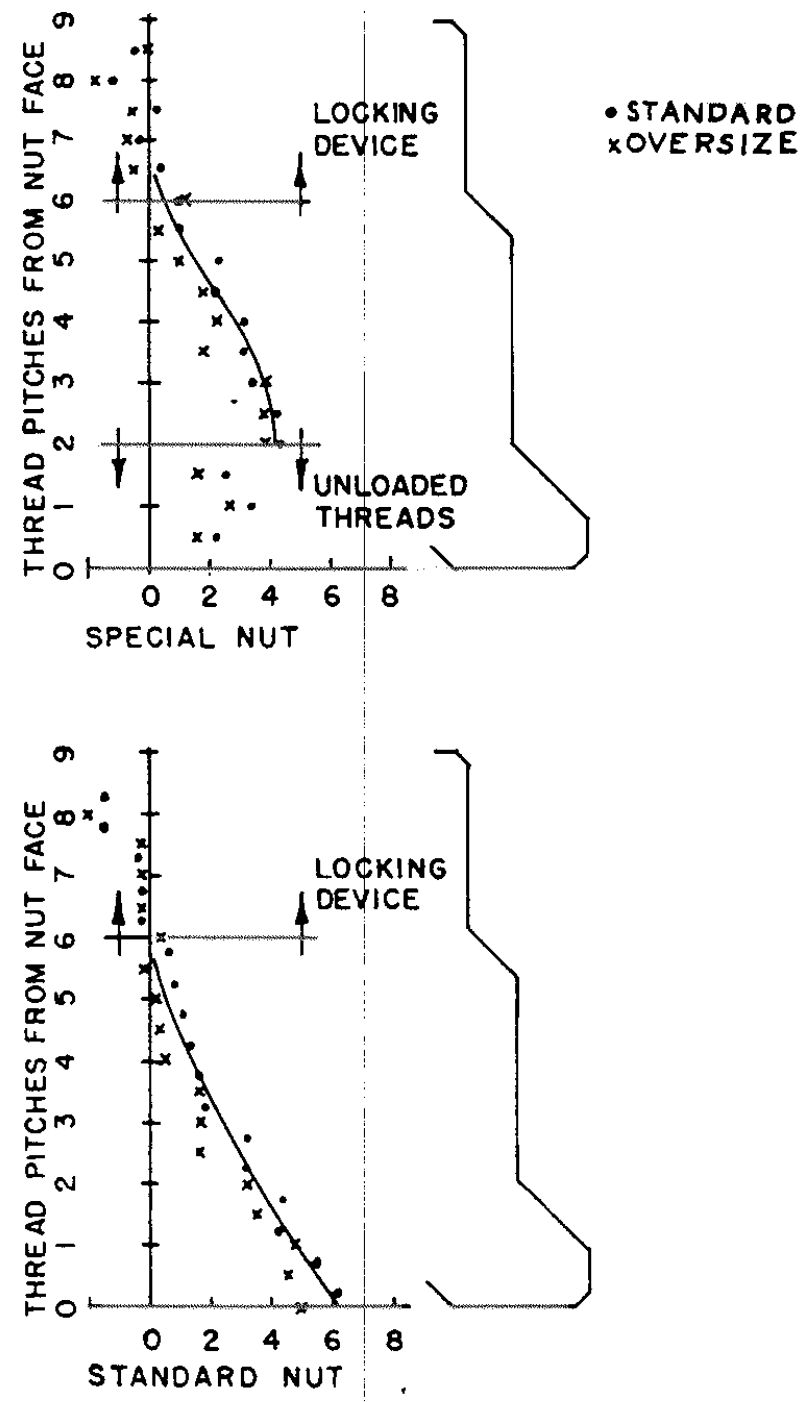

Fig. 6-Maximum fringe counts at bolt thread roots

which mate with the special nuts are not loaded. This has interesting implications which will be discussed in a later paragraph.

\section{Analysis}

The maximum fringe orders recorded for bolt threads loaded by the special nuts are all quite low. They are only slightly larger than the fringe orders recorded for the thread-runout area. For example, the four maxima in bolt threads loaded by the special nuts are $3.8,3.8,4.2$ and 4.5 which can be compared to fringe orders of $3.2,3.7,3.8$ and 2.4 in the runout areas of the oversize-shank bolt. This means that the stress concentrations due to the reduction in area combined with those due to the presence of a notch the thread in the runout area give rise to stresses of the same magnitude as those due to the interaction of the bolt and the special nut.

The low fringe order of 2.4 in one of the thread roots is something of a surprise. It is not known if 
it is clue to some peculiarity of the special nut or due to asymmetric loading of the special nut leading to the low fringe order on one sicle of the bolt. A bending moment is noted in the section containing the low reading and the low reading is on the sime side as the compressive bending stress, so the otserved difference is consistent with the bending moment in the shank of the bolt, but it is doubtful that the large difference in fringe order on the two sides of the section can be attributed to the small amount of bending observed in the shank of the bolt.

Maximum fringe orders in the threads loaded by the standard nuts are substantially higher than those in any other part of the bolts, and it is apparent that the first thread engaged by these nuts carries the greatest load. Additionally, the maximum fringe orders due to the standard nuts are substantially higher than those due to the special nut.

When the thread-root fringe orcler is plotted against the thread position, as wis done in Fig. 6. an idea of the load distribution in the bolt can be obtained. It is appotrent that the special nut distributes the load in the bolt "better" than the standard nut. For the standiard nut, the first loaded thread carries more load than the second: whereas. the first two loaded threads in the other combination carry approximately the same load. The gentle eurvature and the initial slope of the curve for the special nut more closely represents an "ideal" loading curve than does the curve for the standard nut.

\section{Stress-concentration Factors}

In calculating the stress concentrations, it is important to specify the stress to which the local high stresses will be compared. For instance, the stress can be compared to the mean shank stress, the stress based on the pitch-diameter area, or even the stress maximum in the thread-runout region. Each of these values offers useful information. The particular value that suits a certain application is a matter to be determined by the user of the fastener. Average stress-concentration factors based on these three reference stresses are given for the four tested combinations in Table 1.

The first two engaged threads in the special nuts were not loaded. This was an unexpected phenomenon, but one that is of particularly noteworthy

TABLE 1-STRESS.CONCENTRATION FACTORS FOR THE FOUR TEST COMBINATIONS AND THREE REFERENCE STRESSES

$\begin{array}{ccccc}\text { Nut } & \text { Bolt } & \begin{array}{c}\text { Average } \\ \text { shank }\end{array} & \begin{array}{c}\text { Pitch } \\ \text { diameter }\end{array} & \begin{array}{c}\text { Runout- } \\ \text { thread } \\ \text { root }\end{array} \\ \text { Special } & \text { Oversize } & 3.2 & 2.1 & 1.2 \\ \text { Special } & \text { Standard } & 2.7 & 2.9 & 1.4 \\ \text { Standard } & \text { Oversize } & 4.0 & 2.1 & 1.3 \\ \text { Standard } & \text { Standard } & 3.7 & 3.8 & 1.8\end{array}$

significance in this investigation. Some concern had been voiced prior to the tests that the nuts conld easily be threaded too far on the holt in normal applications. This condition has long been recognized as detrimental to optimum service life in bolted joints subject to fatigue loading. because it places the first thread of the nut close to the thread runout area, where the stress concentrations due to nut loading are combined with concentrations due to notch effect. In oversize bolts, these also combine with concentrations due to section change from the oversize shank to thread-root diameter. This means that, in addition to the reduction in induced stress concentration offered by the more flexible threarls in the special nut, this nut effectively loads the bolt away from other areas of high stress concentration.

The results indicate that, for installations in which the special nut is used, bolt geometry will be a controlling factor in determining the fatigue life of the bolt-nut combination, hecause the stressconcentration factors due to the nut are of the same magnitude as the struss-cuncentration factors due solely to bolt geometry. On the other hand, for installations in which standard nuts are used, the nut-induced stress-concentration factors are much larger than those due to holt geometry, and so bolt geometry should have less effect on the fatigue performance of the combination.

\section{Conclusions}

1. Oversize-shank bolts are not rewmmended for fatigue applications. This is true of both tension and shear applications, since it appears that, in the latter, unexplained mechanisms are at work which cause the bolt to be partially loaded in tension.

2. Based on the results reported herein, it would appear that the special nut offers definite improvements in fatigue performance of bolted joints.

\section{Acknowledgments}

The author acknowledges the invaluable assistance rendered him in this project by R. L. Kurtak and R. E. Finigan and other members of the staft of the Technical Support Group of the Structural Research Laboratory, Commercial Airplane Division, The Boeing Company.

\section{References}

1. Stromeyer, C. E., "Stress Distribution in Bolts and Nuts," Trans. Inst. Naval Architects, LX, 112-122, Plates XIII and XIV (1918).

2. Den Hartog, J. P., "The Mechanics of Plate Rotors for 'Turbo Generators," Trans. ASME, APM.5 $t-1,51,1-11$ (1929).

3. Solakian, A. G., "Why Threaded Parts Fail," Produnt Eng. 261-262 (July 1933).

4. Hall. S. G." "Determinction of Stress Concentration in Screu Threads

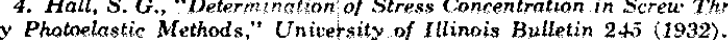
by Phatoelastic Methods," University of Illinois Bulletin 245 (1932).
5. Hevuond, R. B., "Tensile Fillet Stresses in Loaded Prajections," 5. Hevuond, R. B., "Tensile Fillet Stress
Proc. Inst. Mech. Engrs. 159, 384-391 (1948).

6. Goodier, J. N., "The Distribution of Load on the Thregds of Sireus," Jnl. Appl. Mech., A-10-16 (March 19.40).

7. Horger, O. J., and Buckutulter, T. V., "Photoelasticity as Applied to Design Problems." The Iron Age, 42-50 (May 23, 1940).

8. Hetenyi, M., "A Photoelastic Study of Bolt and Nut Fastenings," 8. Hetenyi, M., "A Photoelastic Study of
Jnl. of Appl. Mech., A-93-100 (dune 194:3). 